\title{
Mullite development on firing in porcelain stoneware bodies
}

Jorge Martín-Márquez, Jesús Ma. Rincón, Maximina Romero

Group of Glass and Ceramic Materials, Department of Building Construction Systems, Eduardo Torroja Institute for Construction Sciences-CSIC, 28033 Madrid, Spain

\begin{abstract}
Microstructural evolution on heating was investigated in a reference industrial composition (50\% kaolinitic clay, $40 \%$ feldspar and 10\% quartz) of porcelain stoneware, fast fired at different temperatures $\left(500-1400^{\circ} \mathrm{C}\right)$. The evolution of mullite crystals, regarding shape and size progress, was examined by scanning electron microscopy (SEM). The proportion of Type I mullite crystals decreases with firing temperature and simultaneously, the size of crystals increases, reaching the maximum value of aspect ratio (3:1) at $1400{ }^{\circ} \mathrm{C}$. Type II and Type III secondary mullite needles increase with temperature in both number and length, which leads to an increase in the aspect ratio from 5:1 to $~ 20: 1$ in Type II crystals and from $\sim 33: 1$ to 50:1 in Type III mullite needles. Finally, clusters of Type III mullite fibres are observed in porcelain stoneware samples fast fired in the $1250-1280{ }^{\circ} \mathrm{C}$ interval.
\end{abstract}

\section{Keywords}

Mullite; Porcelain stoneware; Microstructure; Electron microscopy; Traditional ceramics

\section{Introduction}

Porcelain stoneware tile is a vitrified ceramic building material used extensively for floor pavement and wall covering in both indoor and outdoor applications. Porcelain stoneware is characterized by its high technological properties, such as low water absorption $(<0.5 \%)$ and high bending strength (>35 MPa), as well as exceptional aesthetic appearance. These excellent properties have caused ceramic tile factories to multiply production and increase sales of porcelain stoneware significantly compared to all other ceramic building materials.

Commercial porcelain stoneware tiles are produced by fast single firing (60-90 min cold to cold) of a triaxial ceramic composition. A typical porcelain stoneware body is composed of $40-$ 50 wt.\% kaolinitic clay, 35-45 wt.\% feldspar and 10-15 wt.\% quartz sand. ${ }^{1}$ Kaolinitic clay promotes mullite formation on firing and simultaneously it confers plasticity on the green paste 
facilitating shape-forming operations. Feldspar is a low melting mineral and acts as a flux during firing, giving rise to a liquid phase, which improves the growth of mullite crystals, as well as facilitating densification of the ceramic body through filling interconnected pores. Quartz is used as a filler and reduces deformation and shrinkage of fired bodies.

The unfired body is comprised of different micro-regions of varying composition, including quartz particles, clay agglomerates and feldspar-enriched regions. After firing, porcelain stoneware shows a typical grain and bond porcelain microstructure with coarse quartz particles held together by a finer matrix consisting of mullite crystals and a glassy phase. ${ }^{2}$ Depending on the micro-region from which they develop, mullite crystals have varying shapes and sizes in the fired microstructure. Pure clay agglomerate relicts lead to fine cuboidal crystals (termed primary mullite since they form at the lowest temperatures), whereas those regions in which feldspar particles were well mixed with kaolinitic clay or where feldspar has gone through clay agglomerates form elongated needle-shaped crystals termed secondary mullite (since they form later in the firing process). Cuboidal primary mullite crystals formed from pure kaolinite clay are surrounded by a highly viscous matrix. Mass transport for free growth of these crystals is limited and primary mullite shows a low aspect ratio (1-3:1). Mullite crystals derived from feldspar-penetrated clay relicts find a less viscous environment since feldspar develops a fluid liquid phase at low temperatures. The growth of these crystals is easier, so they achieve a high aspect ratio (3-10:1). Finally, mullite needles formed from areas of mixes of fine clay, feldspar and quartz show a very high aspect ratio (30-40:1) since they are surrounding by a more fluid liquid enriched in alkalis, which favours the fast growth of crystals. Iqbal and Lee ${ }^{\text {and }} 3$ highlight that a new notation, considering the aspect ratio, was necessary for mullite crystals formed in porcelain materials. They suggest Type I for cuboidal low aspect (1-3:1) primary mullite, Type II for high aspect ratio (3-10:1) secondary mullite and Type III for very high aspect ratio (30-40:1) secondary mullite needles.

The main difference between porcelain and porcelain stoneware lies in their firing schedule, with lower heating rate in porcelain $\left(10^{\circ} \mathrm{C} / \mathrm{min}\right)$ than in porcelain stoneware $\left(50{ }^{\circ} \mathrm{C} / \mathrm{min}\right)$ processing. Consequently, the microstructure evolution on firing should be different since both crystallized fraction and shape of mullite crystals are very dependent on the heating rate. ${ }^{4}$ The microstructural evolution regarding shape and size progress of mullite crystals on firing has been investigated in kaolin5 $6^{\text {and }} 7$ and triaxial porcelains. 2.8 and 9 However, as for porcelain stoneware tiles, the literature on microstructural investigation is limited to describing mainly porosity evolution10,11,12,13,14,15 and 16 or phases assemblages. $17^{\text {and }} 18$ To the author's knowledge, a study concerning aspect ratio changes in mullite crystals on heating has not been 
carried out in porcelain stoneware bodies. Such a study is needed because enhanced strength and toughness have been reported in porcelains containing increased amounts of high aspect ratio mullite crystals. ${ }^{19} \mathrm{~A}$ better knowledge of the microstructure on firing porcelain stoneware tiles will lead to the optimization of firing process and properties of end-products.

The aim of this paper is to examine the microstructural evolution in a conventional porcelain stoneware body, representative of the industrial production, taking into consideration the aspect ratio changes of mullite crystals on firing.

\section{Materials and methods}

Raw materials used in the present investigation were kaolinitic clay and feldspar (provided by Compañía Europea de Arcillas, S.A. and designed as AR-2097-G and FC-100 respectively), and quartz sand (facilitated by IETcc, CSIC). Chemical and mineralogical compositions of all raw materials were given in a previous paper. ${ }^{20}$ All the above materials were crushed, ground and finally powdered to $<160 \mu \mathrm{m}$ prior to further use.

A typical porcelain stoneware tile composition denoted PSW was prepared by mixing $50 \%$ kaolinitic clay, $40 \%$ feldspar and 10\% quartz. Batches (300 g each) were prepared by milling the constituents with distilled water (1:1) for $30 \mathrm{~min}$, in a planetary ball mill and using alumina balls as grinding media. The slurry was oven-dried overnight at $110{ }^{\circ} \mathrm{C}$, powdered in a porcelain mortar and pestle, and sieved to pass-100 mesh $(150 \mu \mathrm{m})$. Table 1 collects the chemical composition of the as-mixed batch.

Table 1. Chemical composition of the as-mixed porcelain stoneware batch.

\begin{tabular}{cc}
\hline Oxide & Wt.\% \\
\hline $\mathrm{SiO}_{2}$ & 66.88 \\
$\mathrm{Al}_{2} \mathrm{O}_{3}$ & 20.49 \\
$\mathrm{Fe}_{2} \mathrm{O}_{3}$ & 0.84 \\
$\mathrm{CaO}$ & 0.35 \\
$\mathrm{MgO}$ & 0.22 \\
$\mathrm{Na}_{2} \mathrm{O}$ & 0.91 \\
$\mathrm{~K}_{2} \mathrm{O}$ & 4.89 \\
$\mathrm{TiO}_{2}$ & 0.40 \\
$\mathrm{P}_{2} \mathrm{O}_{5}$ & 0.08 \\
Loss on ignition & 4.94 \\
\hline
\end{tabular}


The resulting powder was moistened by spraying with distilled water (6 wt.\%) and uniaxially pressed at $40 \mathrm{MPa}$ in a steel die. Discs of $20 \mathrm{~mm}$ diameter and $5 \mathrm{~mm}$ height were shaped from $3 \mathrm{~g}$ of powder. After drying in an oven at $110{ }^{\circ} \mathrm{C}$ the compacts were placed on alumina rollers in an electric furnace and fired between 400 and $1300{ }^{\circ} \mathrm{C}$ following two different heating schedules. Thus, samples fired at temperatures lower than $1000{ }^{\circ} \mathrm{C}$ were heated from room temperature to the required firing temperature at $50{ }^{\circ} \mathrm{C} / \mathrm{min}$. On the other hand, samples firing at temperatures higher than $1000{ }^{\circ} \mathrm{C}$ were heated from room temperature to $1000{ }^{\circ} \mathrm{C}$ at $50{ }^{\circ} \mathrm{C} / \mathrm{min}$, and from $1000{ }^{\circ} \mathrm{C}$ to the firing temperature at $\sim 20^{\circ} \mathrm{C} / \mathrm{min}$. In all cases, after holding for $15 \mathrm{~min}$ at the maximum temperature, the samples were cooled inside the furnace at $50{ }^{\circ} \mathrm{C} / \mathrm{min}$ to room temperature.

Quantitative full-phase analyses of fired samples using the Rietveld method and including amorphous content were reported previously. ${ }^{21}$ Table 2 shows quantification of all phases in samples fired from 1000 to $1400{ }^{\circ} \mathrm{C}$.

Table 2. Rietveld quantitative phase analysis results including amorphous content for porcelain stoneware body fired at different temperatures.

Temperature $\left({ }^{\circ} \mathrm{C}\right)$

\begin{tabular}{lccccccc} 
& 1000 & 1100 & 1200 & 1230 & 1260 & 1300 & 1400 \\
\cline { 2 - 7 } Mullite & - & 3.6 & 12.2 & 14.4 & 14.5 & 14.0 & 13.7 \\
Quartz & 29.3 & 28.2 & 27.7 & 24.1 & 24.2 & 24.6 & 19.3 \\
$\begin{array}{l}\text { Feldspar } \\
\begin{array}{l}\text { Amorphous } \\
\text { phase }\end{array}\end{array}$ & 21.1 & 15.5 & 3.2 & - & - & - & - \\
& 44.2 & 52.8 & 56.9 & 61.5 & 61.2 & 61.4 & 67.0 \\
Others & 5.3 & - & - & - & - & - & -
\end{tabular}

Phase assemblages and microstructure of fired specimens was examined by scanning electron microscopy (SEM) in a Philips XPERT microscope using an accelerate voltage of 
$20 \mathrm{kV}$. For analysis of phase assemblages and morphology, the fresh fracture surfaces were etched for $4 \mathrm{~min}$ in $15 \% \mathrm{HF}$ solution, washed ultrasonically with distilled water and ethylic alcohol, dried and subsequently Au-Pd coated in a Balzers SCD 050 sputter. Secondary electron images (SEI) and backscattered electron images (BSI) were used for microstructural examination. Semi-quantitative analyses of different phases were obtained by energy dispersive $\mathrm{X}$-ray spectroscopy (EDS) by using a Link eXL detector provided by a beryllium (Be) window.

\section{Results and discussion}

Fig. 1 shows micrographs of PSW fired at $500{ }^{\circ} \mathrm{C}$. The low magnification SEI shows a typical underfiring ceramic microstructure with high-interconnected porosity. At that temperature, kaolinite transforms to metakaolinite by removing the hydroxyl groups as observed by differential thermal analysis (DTA) and X-ray diffraction (XRD) in previous studies.20'21, $22^{\text {and }} 23$ The flaky nature typical of kaolin particles is not observed, nevertheless clay agglomerates could be distinguished by high aluminium peaks and lack of potassium peaks in their EDS analysis. EDS also allows differentiating feldspar particles with higher potassium content, quartz grains with high silicon peaks and a fine matrix of clay, feldspar and quartz. All EDS spectra show $\mathrm{Au}$ and $\mathrm{Pd}$ peaks, which are due to the $\mathrm{Au}-\mathrm{Pd}$ coating performed to improve SEM observations. A similar microstructure is also observed in PSW bodies fired in the 800$1000{ }^{\circ} \mathrm{C}$ temperature interval.

Microstructural changes start to be perceptible in PSW fast fired at $1100{ }^{\circ} \mathrm{C}$ (Fig. 2). At this temperature, two types of agglomerates are differentiated. Granular agglomerates composed only by silica and alumina are commonly termed as pure clay relicts and correspond to regions where pure clay was located in the green body. Higher contrast agglomerates contain alkaline elements (revealed by EDS). They correspond to the so-called clay-feldspar relicts, because they are associated with clay relicts in which feldspar has penetrated. The edges of quartz particles are rounded, indicating their partial dissolution in the incipient liquid phase formed at that temperature. ${ }^{20}$ 


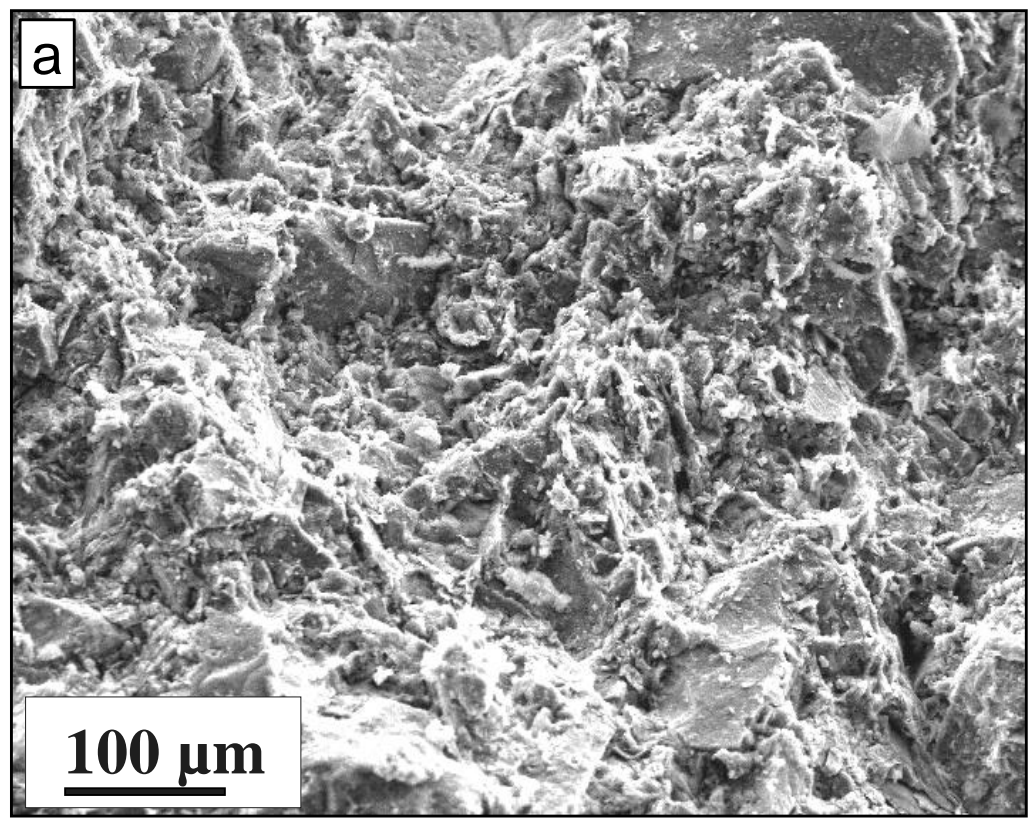

d
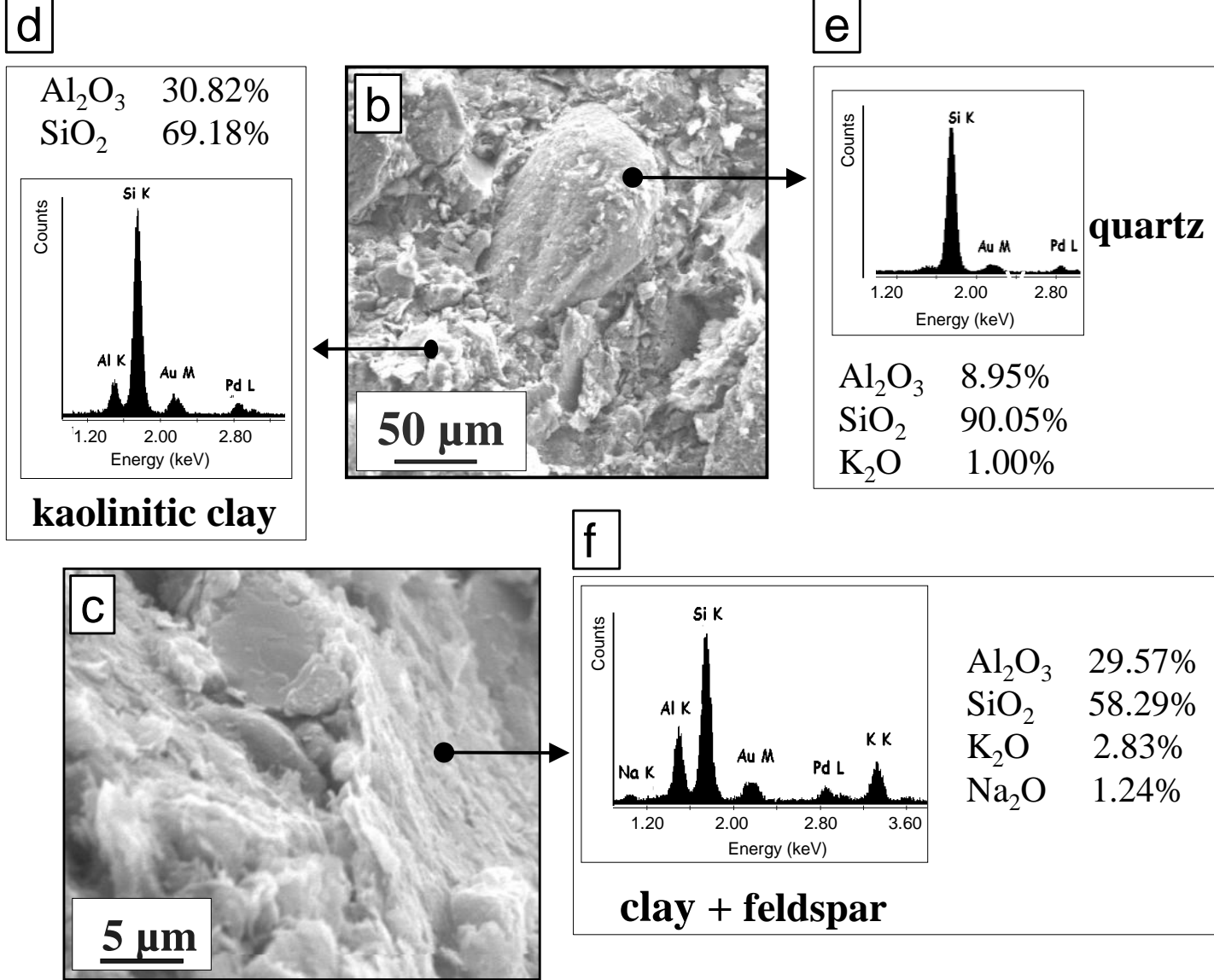

Fig. 1. SEM/SE images of fresh fractured, etched PSW pellets fast fired at $500^{\circ} \mathrm{C}$. (a) Typical underfiring ceramic microstructure with high-interconnected porosity; (b) clay agglomerate and quartz particle; (c) clay + feldspar agglomerates. EDS and semi-quantitative analysis of (d) clay agglomerates; (e) quartz grains and (f) clay + feldspar agglomerates. 

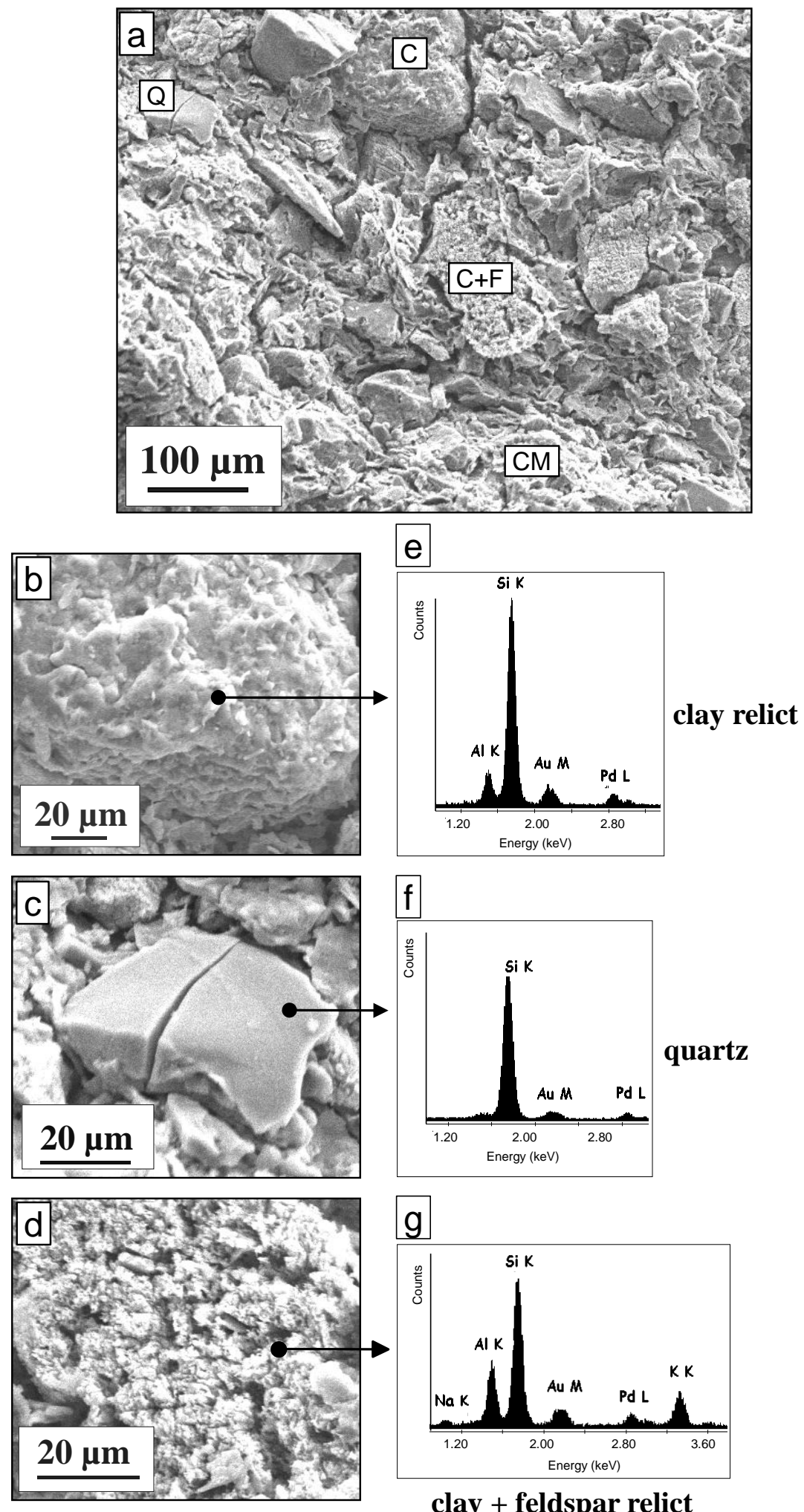

clay + feldspar relict

Fig. 2. SEM/SE images of fresh fractured, etched PSW pellets fast fired at $1100{ }^{\circ} \mathrm{C}$. (a) Q: quartz, C: pure clay relict, CF: clay-feldspar relicts and CM: ceramic matrix; (b) pure clay relict; (c) quartz particle and (d) clay-feldspar relicts. EDS of (e) pure clay relict; (f) quartz particle and (g) clay-feldspar relicts. 
Some of these quartz particles show micro-cracks, likely due to both the $\alpha \rightarrow \beta$ phase transformation of quartz crystals taking place at $\sim 573{ }^{\circ} \mathrm{C}$ during the heating-cooling process and to the relaxation of micro-stresses originated between quartz grains and the surrounding glassy phase by the differences in their thermal expansion coefficients $\left(\alpha \sim 23 \times 10^{-6}{ }^{\circ} \mathrm{C}^{-1}\right.$ for quartz and $\alpha \sim 3 \times 10^{-6}{ }^{\circ} \mathrm{C}^{-1}$ for the glassy phases) in the $20-750{ }^{\circ} \mathrm{C}$ temperature interval. ${ }^{24}$ Quartz grains and different agglomerates are surrounded by a ceramic matrix comprised of a mixture of fine grains of quartz, feldspar and kaolinitic clay. Though Rietveld analysis allowed the quantification of a $3.6 \mathrm{wt} . \%$ of mullite phase at $1100{ }^{\circ} \mathrm{C}$ (Table 2), its formation is not yet revealed by SEM, likely due to the small size of the first developed mullite crystals.

The microstructure of the PSW body fast fired at $1200{ }^{\circ} \mathrm{C}$ (Fig. 3) depicts the typical features of a well-fired ceramic body in which all the physical transformations and chemical reactions between the original raw materials have taken place. It is clearly observed the presence of many areas, which composition, as determined by EDS analysis (Fig. 3b and d), is similar to the potassium feldspar used in the PSW body composition. Rietveld quantification at $1200{ }^{\circ} \mathrm{C}$ (Table 2) had shown lower feldspar content (3.2\%) and PSW is mainly composed by quartz, mullite and amorphous phase. Thus, such regions should correspond to amorphous regions. Furthermore, they show etch pits, which are a typical microstructural feature of etched glasses $^{25}$ and hence, those regions are likely feldspar derived glassy phase. Mullite formation is evident at this temperature. Regions including mullite crystals with two different morphologies are distinguished in the SEI taken at $1200{ }^{\circ} \mathrm{C}$ (Fig. 3c). Small scaly mullite with size lower than $0.2 \mu \mathrm{m}$ is Type I primary mullite derived from pure clay relicts. These crystals show similar morphology to that found in early studies of mullite formation from thermal decomposition of pure kaolinite. $5^{\text {and }} 26$ Moreover, needle-like mullite crystals showing an aspect ratio in the 57.5:1 interval $(\sim 0.5-1.5 \mu \mathrm{m}$ long and $\sim 0.1-0.2 \mu \mathrm{m}$ wide) are also observed corresponding to Type II secondary mullite formed from regions in which feldspar has penetrated clay agglomerates. At $1200{ }^{\circ} \mathrm{C}$ the feldspar component has been significantly reduced (3.2\%) by forming a liquid phase and mullite crystals newly developed in those regions are in a surrounding media with lower viscosity than that around pure clay agglomerates. As a consequence, the growth of mullite crystals through a diffusion mechanism is favoured. ${ }^{2}$ It is important to note that Type I scaly mullite crystals are usually adjacent to regions of Type II needle crystals. This suggests that primary mullite crystals formed at the external surface of pure clay agglomerates could grow out and transform into secondary mullite crystals if they are near a lower viscosity matrix. This result is in agreement with $\operatorname{Lundin}^{27}$ who suggested that 
mullite in the clay relicts serves as seed for the crystallization of mullite needles in the feldspar relicts.
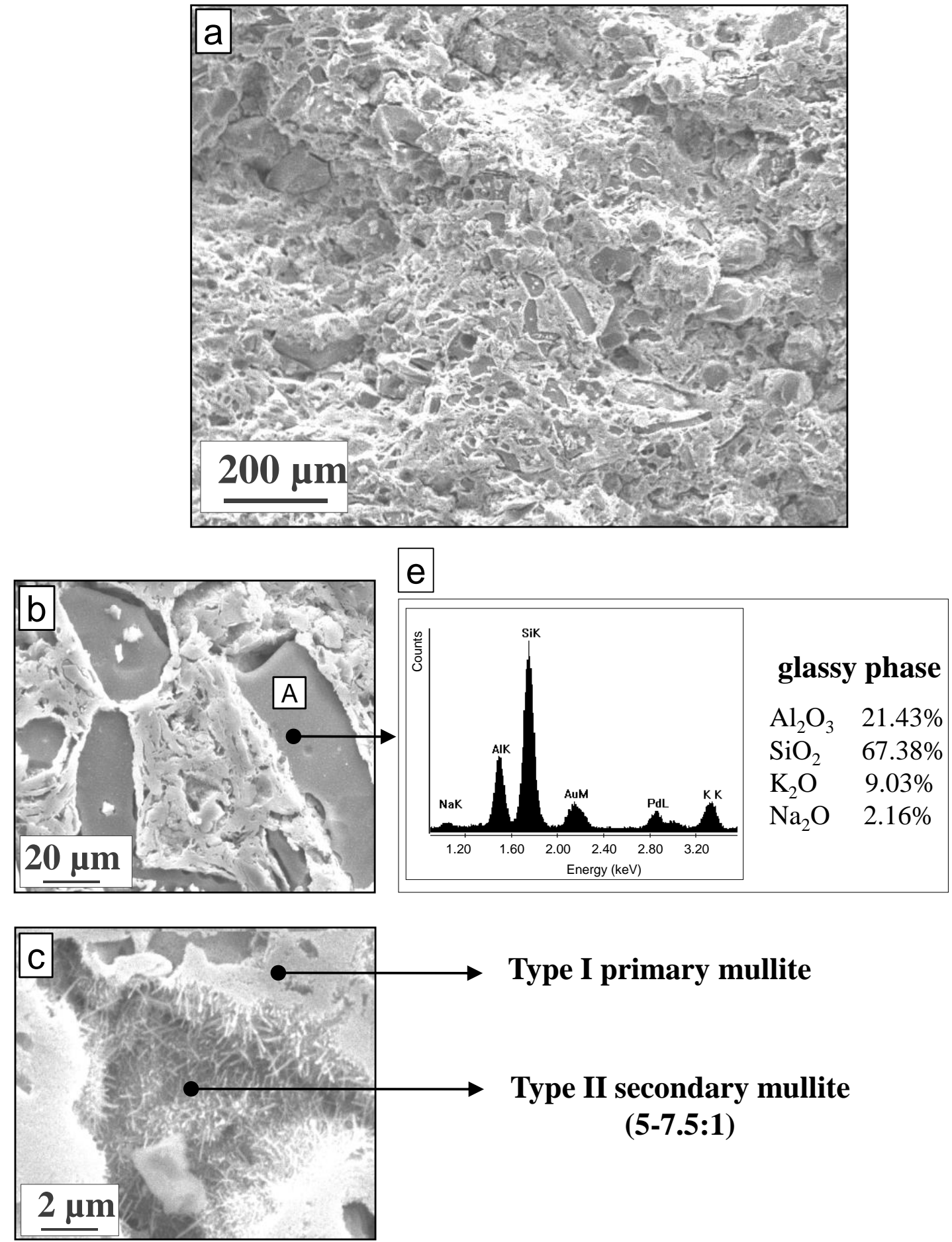

Type I primary mullite

Type II secondary mullite

(5-7.5:1)

Fig. 3. SEM/SE images of fresh fractured, etched PSW pellets fast fired at $1200^{\circ} \mathrm{C}$. (a) General microstructure; (b) A: amorphous regions; (c) mullite regions showing Type II secondary mullite crystals adjacent to regions of Type I primary mullite and (d) EDS and semi-quantitative analysis of the glassy phase. 
At $1230{ }^{\circ} \mathrm{C}$ feldspar has totally decomposed and the PSW body is just comprised simply of mullite crystals, quartz grains and a glassy phase. The microstructure (Fig. 4) of the fast fired body is composed, as at $1200{ }^{\circ} \mathrm{C}$, of quartz grains in a matrix comprised of primary Type I and secondary Type II mullite crystals. Primary mullite crystals are similar to those in the PSW body fired at $1200{ }^{\circ} \mathrm{C}$. However, a clear evolution in both number and size of Type II crystals is observed. More elongated mullite crystals appear than at $1200{ }^{\circ} \mathrm{C}$ sample due to the viscosity of the matrix in which secondary crystals grow. Viscosity is related to both nucleation and crystal growth rate. 28 and 29 The higher the firing temperature the more fluid is the liquid phase formed and the growth of needle-like crystals throughout their longitudinal axis is favoured in such way that mullite crystals show similar width to those developed at lower temperature but greater length (up to $\sim 4 \mu \mathrm{m}$ ), and consequently their aspect ratio increases up to maximum values of $\sim 20: 1$. This result suggests that the increase in mullite percentage determined by Rietveld method (Table 2) is mainly due to the increase in secondary Type II mullite formation. As for quartz particles, micro-cracks are only observed inside grains larger than $>30 \mu \mathrm{m}$, which indicates that cracking is associated with the particle size. ${ }^{30}$ Small quartz grains in the ceramic matrix can be clearly identified in BSI by their surrounding dark rim commonly termed as amorphous silica solution rim from dissolution of quartz grain edges. ${ }^{31}$

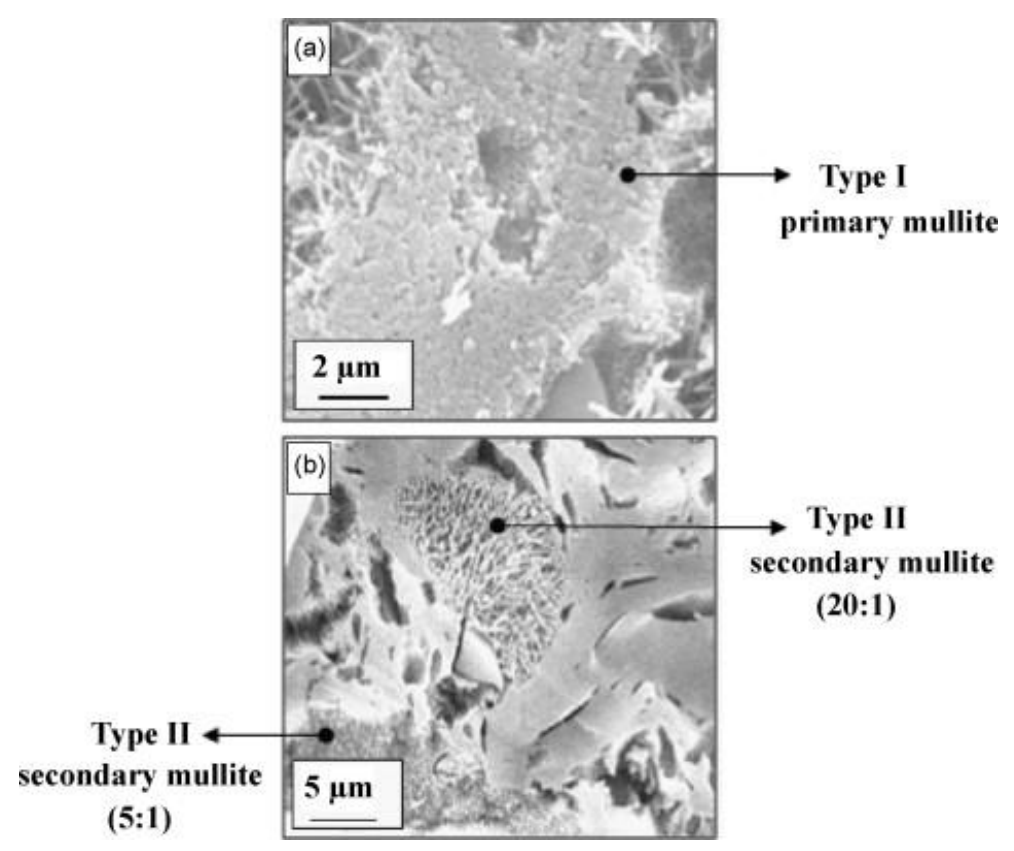

Fig. 4. SEM images of fresh fractured, etched PSW pellets fast fired at $1230^{\circ} \mathrm{C}$. (a) SE image of Type I primary mullite and (b) BS image of Type II secondary mullite with aspect ratio from 5:1 to 20:1. 
Greater longitudinal growth of mullite crystals is still observed in PSW bodies fast fired at $1250{ }^{\circ} \mathrm{C}$ (Fig. 5). Together with Type I and Type II crystals, mullite needles reaching lengths up to $\sim 6-8 \mu \mathrm{m}$ and aspect ratio in the $\sim 33-44: 1$ interval, are formed. They correspond to secondary Type III mullite crystals derived from the ceramic matrix, which is the region with the lower viscosity because it is comprised of a homogeneous mixture of small size particles of quartz, feldspar and clay. Besides the former mullite crystals, at $1250{ }^{\circ} \mathrm{C}$ even larger needles start to appear, which show a considerable growth in both longitudinal and axial axes, reaching lengths and widths in the $\sim 18-22 \mu \mathrm{m}$ and $\sim 1-1.5 \mu \mathrm{m}$ interval respectively. Thus, the aspect ratio of these needles is in the $\sim 15-18: 1$ range. By considering the notation proposed by Iqbal and Lee ${ }^{31}$ these crystals could not be considered as secondary Type III mullite (30-40:1 aspect ratio) neither as Type II mullite because of their length. A detailed observation of this growth suggests that the crystals are comprised of several needles of lower width. It appears that secondary Type III mullite fibres, with aspect ratio $>30: 1$, join together and give rise to clusters or packs of needles. A similar morphology has been described in triaxial porcelains with partial substitution of fly ash by quartz ${ }^{32}$ but it has not been described before in porcelain stoneware tiles. Although Rietveld quantification had shown no changes in the percentage of mullite phase in the $1230-1260{ }^{\circ} \mathrm{C}$ temperature interval, the microstructural study by SEM clearly shows that mullite crystals are experiencing important morphological changes.

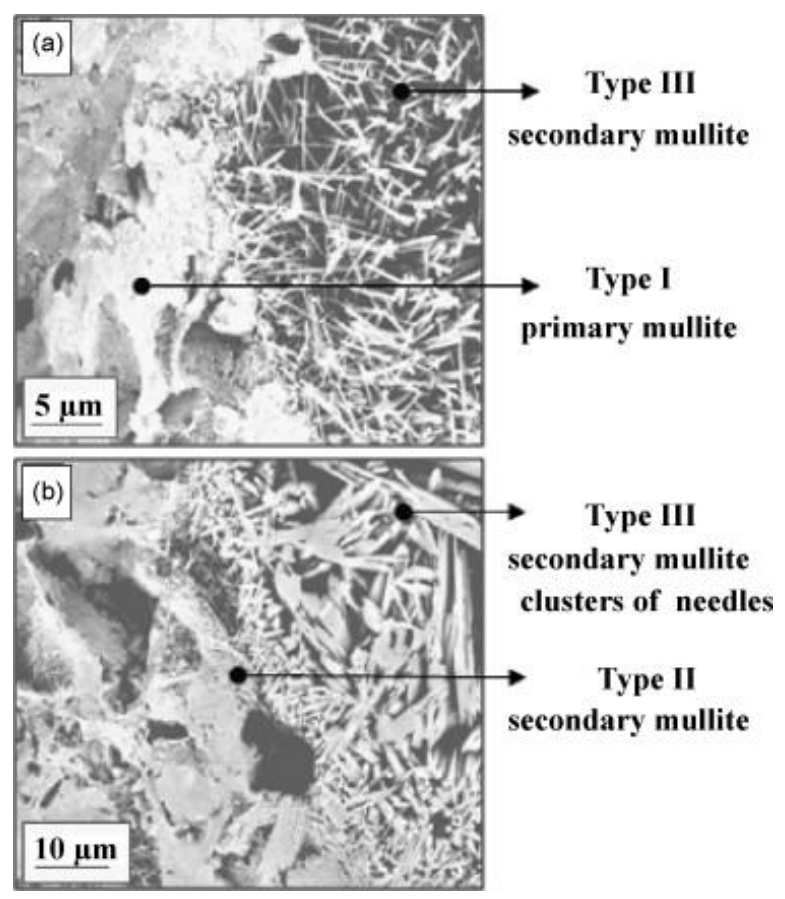

Fig. 5. SEM/BS images of fresh fractured, etched PSW pellets fast fired at $1250{ }^{\circ} \mathrm{C}$. (a) Type I primary mullite and Type III secondary mullite and (b) Type II secondary mullite and clusters of Type III secondary mullite needles. 
PSW bodies fast fired in the $1260-1280{ }^{\circ} \mathrm{C}$ temperature interval (Fig. 6) show similar microstructure to that depicted by samples fired at $1250{ }^{\circ} \mathrm{C}$. The different crystals of mullite (Type I, Type II and Type III) as well as the packing of Type III needles are clearly distinguished and the main change in the body microstructure results from the different percentages of mullite crystals with temperature. Thus, higher firing temperatures lead to an increase in the development of secondary Type II and Type III needles and the formation of scaly primary Type I mullite simultaneously decreases.
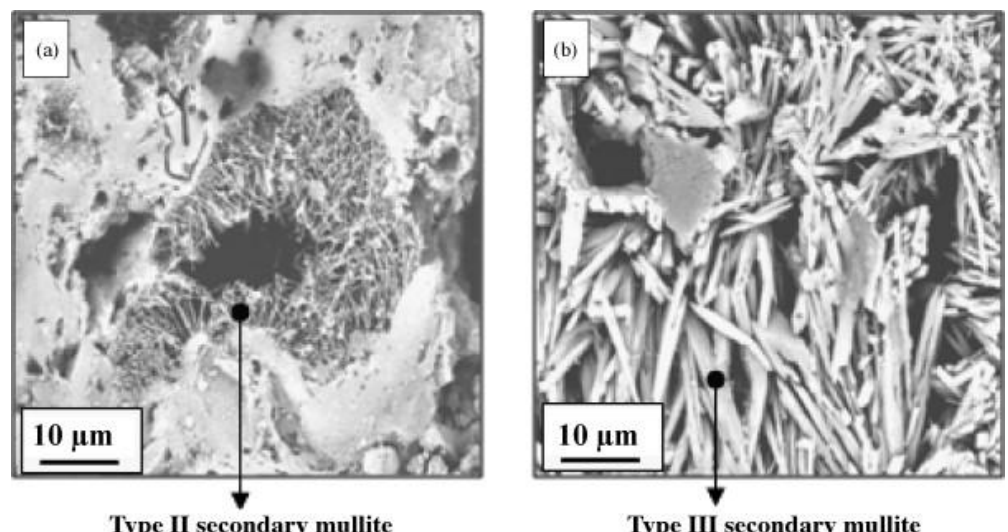

Type III secondary mullite clusters of needles
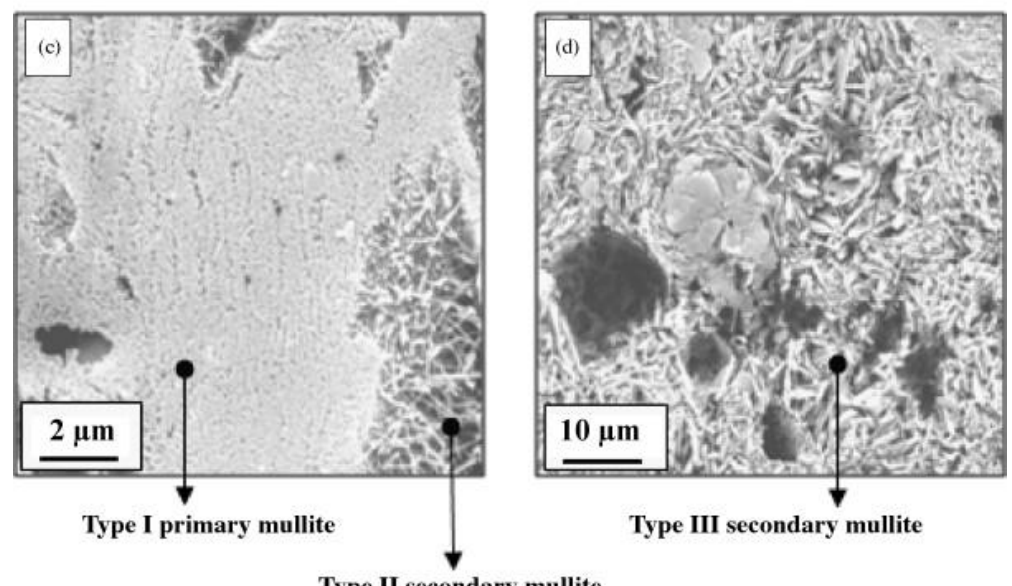

Type III secondary mullite

Type II secondary mullite

Fig. 6. SEM/SE images of fresh fractured, etched PSW pellets fast fired in the $1260-1280{ }^{\circ} \mathrm{C}$ interval. (a) Type II secondary mullite crystals in PSW fired at $1260^{\circ} \mathrm{C}$; (b) clusters of Type III secondary mullite needles in samples fired at $1270{ }^{\circ} \mathrm{C}$; (c and d) Type I primary and Type III secondary mullite in PSW fired at $1280{ }^{\circ} \mathrm{C}$.

Finally, PSW bodies fast fired in the $1300-1400{ }^{\circ} \mathrm{C}$ interval (Fig. 7) show an important increase in the glassy phase content. At such temperatures, secondary Type III mullite crystals are still formed and their length increases and reaches and aspect ratio of 50:1. Nevertheless, clusters of Type III needles observed at lower temperatures are not longer observed. Regarding 
primary Type I mullite formation, an increase in the size of scaly crystals is observed, reaching $\sim 0.6 \mu \mathrm{m}$ long and $\sim 0.2 \mu \mathrm{m}$ wide at $1400^{\circ} \mathrm{C}$. Thus, these crystals show an aspect ratio of $3: 1$, which is the limit between Type I and Type II crystals. ${ }^{31}$

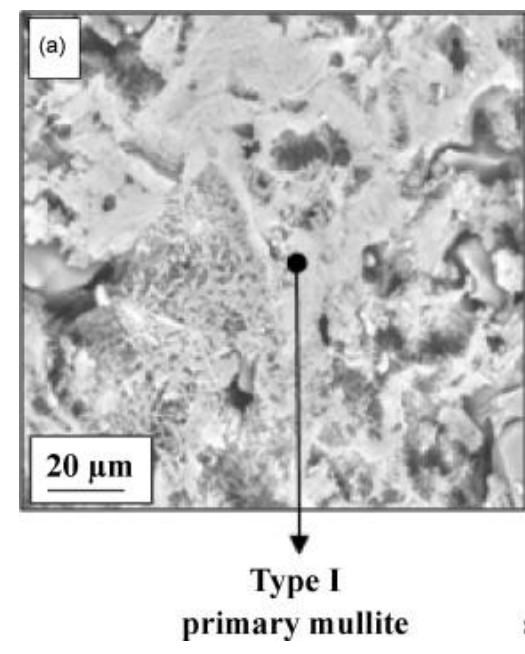

primary mullite

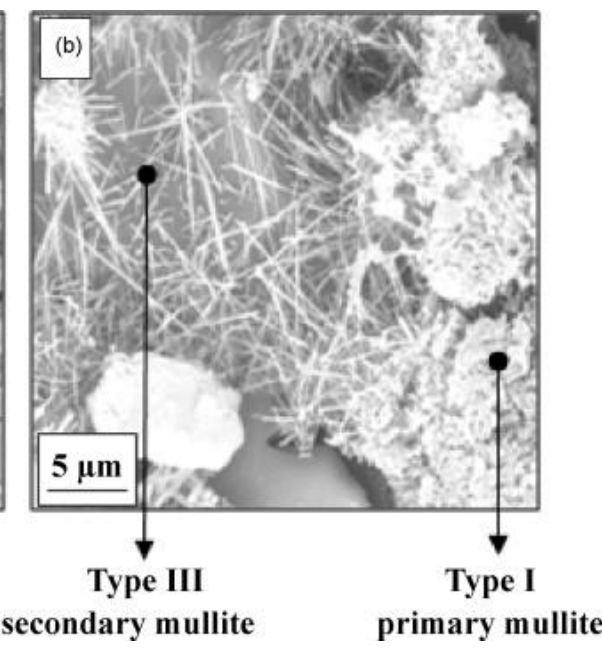

Fig. 7. SEM images of fresh fractured, etched PSW pellets fast fired in the $1300-1400{ }^{\circ} \mathrm{C}$ interval. (a) SE image of Type I primary mullite in PSW fired at $1300{ }^{\circ} \mathrm{C}$ and (b) BS image of Type I primary and Type III secondary mullite in samples fired at $1400^{\circ} \mathrm{C}$.

\section{Conclusions}

A mixture of $50 \%$ kaolinitic clay, $40 \%$ feldspar and $10 \%$ quartz was selected as a representative composition of commercial porcelain stoneware (PSW) tiles produced via a fastfiring process. PSW samples fired in the $500-1000{ }^{\circ} \mathrm{C}$ interval show a typical underfired ceramic microstructure comprised of clay agglomerates, feldspar particles, quartz grains and a fine matrix of clay, feldspar and quartz. At $1100{ }^{\circ} \mathrm{C}$ mullite formation is not yet detected by SEM and the microstructure consists of pure clay relicts, clay-feldspar relicts and quartz particles, agglomerated in a surrounding ceramic matrix.

Mullite development is evident in PSW body fast fired from $1200{ }^{\circ} \mathrm{C}$. After examining the changes in their morphology, the following conclusions can be made:

- $\quad$ Type I primary mullite comprised of small scaly crystals $(0.2-0.6 \mu \mathrm{m}$ long and $\sim 0.2 \mu \mathrm{m}$ wide), is developed in the $1200-1400{ }^{\circ} \mathrm{C}$ interval. The proportion of Type I crystals decreases with firing temperature and simultaneously, the size of crystals increases, reaching an aspect ratio of $3: 1$ at $1400{ }^{\circ} \mathrm{C}$, which is the limit between Type I and II crystals.

- Type II secondary mullite consists of needle-like crystals, and is formed in the $1200-1400{ }^{\circ} \mathrm{C}$ interval. Higher firing temperatures lead to an increase in both 
the number and length of Type II crystals, and the aspect ratio increases from the minimum value of $5: 1$ at $1200{ }^{\circ} \mathrm{C}$ to a maximum value of $\sim 20: 1$ in the $1260-1400{ }^{\circ} \mathrm{C}$ interval.

- Type III mullite crystals, derived from the lower viscosity ceramic matrix, are developed in the $1250-1400{ }^{\circ} \mathrm{C}$. As in Type II, the proportion and length of Type III crystals increase with increasing temperatures, and the aspect ratio rises from $\sim 33: 1$ at $1250{ }^{\circ} \mathrm{C}$ to a value of $50: 1$ in the $1300-1400{ }^{\circ} \mathrm{C}$ interval.

- The spatial arrangement of Type I and Type II crystals suggests that primary mullite crystals formed at the external surface of pure clay agglomerates could grow out and transform into secondary mullite crystals if they are near a lower viscosity environment.

- Clusters or packs of Type III mullite fibres are observed in the $1250-1280^{\circ} \mathrm{C}$ interval.

\section{Acknowledgements}

This research was supported by the Spanish Science and Technology Ministry (ProjectsMAT2000-1422 and MAT2003-2915). The authors gratefully acknowledge Compañía Europea de Arcillas, S.A. for providing raw materials. The authors thank IRICA from University of Castilla-La Mancha (Spain) for experimental assistance.

\section{References}

1. F. Andreola, L. Barbieri, A. Corradi, I. Lancellotti, T. Manfredini. Utilisation of municipal incinerator grate slag for manufacturing porcelainized stoneware tiles manufacturing. J Eur Ceram Soc, 22 (2002), pp. 1457-1462.

2. Y. Iqbal, E.J. Lee. Microstructural evolution in triaxial porcelain. J Am Ceram Soc, 83 (2000), pp. 3121-3127.

3. E.J. Lee, Y. Iqbal. Influence of mixing on mullite formation in porcelain. J Eur Ceram Soc, 21 (2001), pp. 2583-2586.

4. M. Romero, J. Martín-Márquez, J.Ma. Rincón. Kinetic of mullite formation from a porcelain stoneware body for tiles production. J Eur Ceram Soc, 26 (2006), pp. 1647-1652.

5. C.J. McConville, W.E. Lee, J.H. Sharp. Microstructural evolution in fired kaolinite. Br Ceram Trans, 97 (1998), pp. 162-168.

6. O. Castelein, R. Guinebretière, J.P. Bonnet, P. Blanchart. Shape, size and composition of mullite nanocrystal from a rapidly sintered kaolin. J Eur Ceram Soc, 21 (2001), pp. 2369-2376.

7. C.Y. Chen, W.H. Tuan. Evolution of mullite texture on firing tape-cast kaolin bodies. J Am Ceram Soc, 85 (2005), pp. 1121-1126.

8. S.P. Chaudhuri, P. Sarkar. Constitution of porcelain before and after heat-treatment. Part II: Aspect ratio and size-distribution of mullite.J Eur Ceram Soc, 16 (1996), pp. 851-855. 
Jorge Martín-Márquez, Jesús Ma. Rincón, Maximina Romero, Mullite development on firing in porcelain stoneware bodies. Journal of the European Ceramic Society Volume 30, Issue 7, May 2010, Pages 15991607; doi:10.1016/j.jeurceramsoc.2010.01.002

9. W.E. Lee, G.P. Souza, C.J. McConville, T. Tarvornpanich, Y. Iqbal. Mullite formation in clays and clay-derived vitreous ceramics. J Eur Ceram Soc, 28 (2008), pp. 465-471.

10. M.J. Orts, A. Escardino, J.L. Amorós, F. Negre. Microstructural changes during the firing of stoneware floor tiles. Appl Clay Sci, 8 (1993), pp. 193-205.

11. M. Dondi, B. Fabbri, T. Manfredini, G.C. Pellacani. Microstructure and mechanical properties of porcelainized stoneware tiles. C. Palmonari (Ed.), Fourth euro ceramics, Faenza Editrice S.p.A., Faenza, Italy (1995), pp. 319-326.

12. M. Dondi, G. Ercolani, C. Melandri, C. Mingazzini, M. Marsigli. The chemical composition of porcelain stoneware tiles and its influence on microstructural and mechanical properties. Interceramics, 48 (1999), pp. 75-83.

13. C. Leonelli, F. Bondioli, P. Veronesi, M. Romagnoli, T. Manfredini, G.C. Pellacani, et al. Enhancing the mechanical properties of porcelain stoneware tiles: a microstructural approach. J Eur Ceram Soc, 21 (2001), pp. 785-793.

14. J. Trpčevská, J. Briančin, L. Medvecký, K. Ďurišinová. Microstructure and porcelain stoneware properties. Key Eng Mater, 223 (2002), pp. 265-268.

15. P.M.T. Cavalcante, M. Dondi, G. Ercolani, G. Guarini, C. Melandri, M. Raimondo, et al. The influence of microstructure on the performance of white porcelain stoneware. Ceram Int, 30 (2004), pp. 953-963.

16. A. Tucci, E. Rambaldi, L. Esposito. Use of scrap glass as raw material for porcelain stoneware tiles. Adv Appl Ceram, 105 (2006), pp. 40-45.

17. A. Kara, F. Özer, K. Kayaci, P. Özer. Development of a multipurpose tile body: phase and microstructural evolution. J Eur Ceram Soc, 26 (2006), pp. 3769-3782.

18. A. Tucci, L. Esposito, L. Malmusi, E. Rambaldi. New body mixes for porcelain stoneware tiles with improved mechanical characteristics. J Eur Ceram Soc, 27 (2007), pp. 1875-1881.

19. S.P. Chaudhuri. Ceramic properties of hard porcelains in relation to mineralogical composition and microstructure: VI thermal shock resistance and thermal expansión. Trans Ind Ceram Soc, XXXIV (1975), pp. 30-34.

20. J. Martín-Márquez, J.Ma. Rincón, M. Romero. Effect of firing temperature on sintering of porcelain stoneware tiles. Ceram Int, 34 (2008), pp. 1867-1873.

21. J. Martín-Márquez, A.G. De la Torre, M.A.G. Aranda, J.Ma. Rincón, M. Romero. Evolution with temperature of crystalline and amorphous phases in porcelain stoneware. J Am Ceram Soc, 92 (2009), pp. 229-234.

22. T. Tarvornpanich, G.P. Souza, W.E. Lee. Microstructural evolution in clay-based ceramics I: single components and binary mixtures of clay, flux and quartz filler. J Am Ceram Soc, 91 (2008), pp. 2264-2271.

23. T. Tarvornpanich, G.P. Souza, W.E. Lee. Microstructural evolution in clay-based ceramics II: ternary and quaternary mixtures of clay, flux and quartz filler. J Am Ceram Soc, 91 (2008), pp. 2272-2280.

24. Y. Ohya, Y. Takahashi. Acoustic emission from a porcelain body during cooling. J Am Ceram Soc, 82 (1992), pp. 445-448.

25. P.N. Homer, B.J. Crawford. The microstructure of etched glass surfaces. Glass Technol 1970; 11:10-4.

26. C.Y. Chen, G.S. Lan, W.H. Tuan. Microstructural evolution of mullite during the sintering of kaolin powder compacts. Ceram Int, 26 (2000), pp. 715-720.

27. S.T. Lundin. Studies on triaxial whiteware bodies. Almqvist and Wiksell, Stockholm, Sweden (1959). 
Jorge Martín-Márquez, Jesús Ma. Rincón, Maximina Romero, Mullite development on firing in porcelain stoneware bodies. Journal of the European Ceramic Society Volume 30, Issue 7, May 2010, Pages 15991607; doi:10.1016/j.jeurceramsoc.2010.01.002

28. J.Ma. Rincón. Principles of nucleation and controlled crystallization of glasses. Polym Plast Technol Eng, 31 (1992), pp. 309-357.

29. W. Hölland, G. Beall. Glass-ceramic technology. The American Ceramic Society, Ohio (2002).

30. S.I. Warshaw, R.J. Seider. Triaxial porcelains-strength and microstructural relations. R.M. Fulrath, J.A. Pask. (Eds.), Ceramic microstructures, their analysis, significance and production, Wiley, New York (1966).

31. Y. Iqbal, W.E. Lee. Fired porcelain microstructures revisited. J Am Ceram Soc, 82 (1999), pp. 3584-3590.

32. K. Dana, S. Das, S.K. Das. Effect of substitution of fly ash for quartz in triaxial kaolin-quartzfeldspar system. J Eur Ceram Soc, 24 (2004), pp. 3169-3175. 